\title{
Zur Anatomie und Pathogenese des Dacryops.
}

\author{
Von \\ Dr. med. O. Lange, \\ Augenarzt am Herzogl. Krankenhause in Braunschweig. \\ Hierzu Taf. XXV.
}

V. Francke hat in seiner Arbeit über Dacryops (v. Graefe's Archiv f. Ophthalm. XLII. 1.) die in Betracht kommende spärliche Literatur zusammengestellt. Hinzufügen will ich jenem Literaturverzeichniss nur, dass auch Jüngken in seinem Buche (Die Lehre von den Angenkrankheiten, Berlin 1842. S. 438 u. 439) sich über den Dacryops und zwar in eingehenderer Weise als die meisten anderen Autoren auslässt. Jüngken, der übrigens gleich J. Beer den Dacryops als Thränensackgeschwulst bezeichnet, sagt: „Der Dacryops ist eine dem Hygrom ähnliche Geschwolst im oberen Augenlide nach dem äusseren Augenwinkel $\mathbf{z u}$, welche mit einem Ausführungsgange der Thränendrüse in Verbindung steht und durch Verschliessung der Oeffnung des letzteren entsteht, indem sich über der Atresie die Wände des Ausführungsganges zu einer sackartigen Geschwulst erweitern. Dem Entstehen des Dacryops müssen demnach solche Ursachen vorausgegangen sein, welche eine organische Verschliessung der Oeffnungen der Ausführungsgänge der Thränendriisse bewirken können, als heftige in Eiterung übergehende Entzündungen oder mechanische Verletzungen." $O b$ Jüngken selbst den Dacryops beobachtet, ist aus seinen Angaben nicht mit Sicherheit $\mathrm{zu}$ ersehen, jedenfalls führt er keine einzelnen Fälle an. Die sich bei J. Beer findenden Angaben über Dacryops (Lehre ron den Augenkrankheiten, Bd. II. S. 591. Wien 1817) sind insofern auffallend, als die sechs Fälle, die er beobachtet hat, sich nur auf jugendliche Individuen zwischen vier bis zehn Jahren beziehen, wogegen alle anderen bekannt gewordenen Fälle von Dacryops, es sind mit dem unten ge- 
schilderten im Ganzen 15, nur bej erwaclsenen und zwar älteren Leuten beobachtet worden sind.

In dem von mil beobachteten Falle, handelte es sich um eine Frau von 52 Jahren. Patientin gab an, seit circa einem Jahre unter dem äusseren Theile des rechten oberen Augenlides eine Geschwulst zu bemerken, welehe beim Weinen stark ansehwillt und dann im äusseren Theil der Lidspalte sichtbar wird, für gewöhnlich aber unter dem oberen Augenlide, dieses leicht vorwölbend, versteckt bleibt. Patientin klagte über zeitweiliges lästiges Gefühl von Spannung im rechten Auge, das sich beim Weinen erheblich steigert; im Uebrigen fühlt sie sich vollkommen gesund, insbesondere hat sie niemals eine Augenerkrankung durchgemacht, auch will sie sich das Auge niemals verletzt haben.

Die Untersuchung der Augen ergab:

Bei Betrachtung des rechten Auges fällt eine deutliche Anschwellung des äussersten Theiles des oberen Augenlides auf; das Auge selbst zeigt ganz normale Verhältnisse. Zieht man die äussere Lidcommissur stark nach aussen und oben, so präsentirt sich eine bohnengrosse, ovale, bläulich-rothe, halb durchsichtige, cystische Geschwulst, deren conjunctivaler Ueberzug stark vaseularisirt ist. Der Tumor ist anf seiner Unterlage, der Sklera, noch oben und hinten leicht verschieblich, fuhlt sich prallgespannt an und zeigt deutliche Fluctuation; nach oben. lässt sich derselbe nicht abgrenzen, sondern geht in die obere Uebergangsfalte uber. Nach Ektropionirung des oberen Augenlides ist das Bild im Wesentlichen dasselbe, nur dass dann ein noch grösserer Theil der Cyste dem Beschauer zugänglich wird. - Eine auch noch so kleine Oeffinung an der Oberfläche des Tumors, wie sie v. Graefe (Arch. f. Ophthalm. VII. 2. S. 1) beobachtet hat, konnte ich nicht nachweisen, anch gelang es mir nicht durch starken Druck auf die Geschwulst Cystenflüssigkeit zu entleeren. Als ich Patientin Senföl zu riechen gab um die Thränendrise zu stärkerer Secretion anzuregen, schwoll der kleine Tumor bis auf Haselnussgrösse an, hob den äusseren Theil des oberen Lides rom Bulbus stäkker $a b$ und wurde im äusseren Lidwinkel sichtbar; dabei empfand Patientin einen lästigen Druck im rechten Auge. Gleichzeitig bemerkte ich eine leichte Vorwölbung des äussersten Abschnittes des Oberlides auch des linken Auges. Bei genauerem Zusehen zeigte sich in der Tiefe des äusseren Lidwinkels des linken Auges ein kleiner, erbsengrosser, bläulich-rother, cystischer Tumor, der dem des rechten Auges sehr ähnlich sah. Trotz seiner 
Kleinheit war auch dieser in Folge zeitweiligen Anschwellens der Patientin bereits anfgefallen.

Bei dem so typischen Befunde war die Diagnose auf Dacryops leicht zu stellen; ich schlng die operative Entfernung des wechtseitigen Tumors vor. - Unter Cocaïnanaesthesie trug ich den "Tumor, soweit ich desselben habhaft werden konnte, mit Scheere und Pincette $a b$, wobei sich der Cysteninhalt als gelbliche, klare Flüssigkeit in toto entleerte. Die Blutung war ziemlich stark, stand aber sehr bald nach Tamponade der ziemlieh grossen Wundfäehe. Die Wunde heilte unter einem Verbande per primam. Da ich Patientin nur acht Tage post operationem beobachten konnte und sie später nicht melu gesehen habe, so nehme ich an, dass die Beseitigung des Tumors eine definitive war.

Nachdem der abgetragene Theil der Cyste in Formol und Alkohol gehärtet war, bettete ich denselben in Celloïdin ein und zerlegte ihn mit dem Mikrotom in verticaler Riehtung von hinten nach vorn in eine fortlaufende Reihe von Serienschnitten: gefärbt wurden dieselben mit Haematoxylin, Hematoxylin und Eosin, Alaunearmin und Bismarckbraun. - Die milsroskopische Untersuchung der Sehnitte ergab, je nachdem welchem Theile der Cyste dieselben entstammeten, verschiedene Bilder. -- Einige Schnitte hatten den, den Dacryops bildenden, eystisch erweiterten Ansführungsgang der Thränendrüse in seinem ganzen Verlaufe bis zn seiner in der oberen Uebergangsfalte der Conjunctiva liegenden Mündung getroffen und boten besonders instructive, meines Wissens bisher nicht bekannt gewordene Bilder. - Die von mir genan nach diesen Präparaten bei eirca 100 facher Vergrösserung angefertigte Zeichnung (ef. Tafel XXV) will mir so weit instructir scheinen, đass eine eingehendere Beschreibung derselben überflüssig sein dürfte. Man erkennt auf derselben den stark erweiterten, durch den Härtungsprocess geschrumpften Ausfülurungsgang der Thränendrüse, dessen conjunctivale Mündung. durch einen festen Pfropf zum grössten Theil verlegt ist. Betrachtet man das Präparat genauer, so erkennt man, dass dem einsehichtigen Epithelüberzuge des Ausführungsganges an verschiedenen, ganz umschriebenen Stellen einige abgestossene Epithelzellen anhaften. Bei stärkerer Vergrösserung erkennt man in dem Epithelüberzuge der Oystenwand zwischen den einzelnen Zellen desselben recht zahireiche mehrkernige Leukocyten. Der sich in der Mündung des erweiterten Ausführungsganges findende Pfropf besteht aus einer amorphen, feinkörnigen Masse, in der vereinzelte, abgestorbene und auch nock 
lebensfähige, mit gut färbbarem Kerne ausgestattete Epithelzellen liegen. - Die die Wandung des cystisch erweiterten Ausführungsganges der Thränendrüse überziehende Bindehaut zeigt besonders in der Nachbarschaft ihrer Gefässe, zahlreiche zu grösseren und kleineren Haufen angeordnete mehkernige Leukocyten; die Blutgefässe der Conjunctiva sind erweitert, das Bindegewebe erscheint aufgelockert, der conjunetivale Epithelüberzug entlält zahlreiche Leukocyten, desgleichen finden sich solche in grösseren Mengen unter demselben.

Die Entstehung des von mir beobachteten Dacryops dürfte dahin zu deuten sein, dass sich aus unbekannter Ursache ein desquamativer Katarrh eines Ausführungsganges der Thränendrüse eingestellt hat, dass die von seinem Epithelüberzuge abgestossenen Epithelzellen durch die, normaler Weise denselben passirende Thränenflüssigkeit der Mündung des Canals in grösserer Menge zugeführt wurden, und dass diese das Ende des Ansführungsganges, wenn nicht ganz verlegt, so doch so weit verengt hatten, dass die secernirten Thränen oberhalb der verengten Stelle desselben sich stauen und die Wand des Canals cystiseh ausdelhnen mussten; der Dacryops muss also auch in meinem Falle als typische Retentionscyste aufgefasst werden. - $O b$ der das terminale Ende des Ausführungsganges der Thränendrüse verlegende Pfropf von der ersten Ausbildung der Cyste an immer derselbe geblieben ist, oder $o b$ er von Zeit zu Zeit durch den Druck der sich hinter ihm stauenden Thränen ausgestossen und dann immer wieder durch einen neugebildeten ersetzt worden, dürfte sich wohl mit Sicherheit kaum entscheiden lassen; immerhin muss der sich in meinem Präparat findende Pfropf, seiner Structur nach zu urtheilen, als ein Gebilde älteren Datums betrachtet werden. - Da Francke auf Grund seiner anatomischen Untersuchung den von ihm beobachteten Dacryops, auf narbige Schrumpfung des peripheren Endes des Ausführungsganges der Thränendrüse zurückgeführt, so geht daraus nur hervor, dass das ursächliche, zur Retention der Thränen im Ausführungsgange der Drüse führende anatomische Moment in den einzelnen Fällen von Dacryops ein verschiedenes sein kann. Dass ein Trauma bei der Pathogenese des Dacryops gelegentlich eine Rolle spielen kann, will ich in keiner Weise in $\mathrm{Ab}$ rede stellen, in meinem Falle lag jedenfalls ein nachweisbares Trauma nicht vor, und dürfte anch die, meines Wissens, in meinem Falle zum ersten Male beobachtete Doppelseitigkeit des Leidens gegen einen tramatischen Uxsprung desselben 
sprechen. - Letzteres Verhalten legt einem den Gedanken nahe, $o b$ es sich nicht um eine congenitale Anomalie handeln könnte. - Die von Jüngken ausgesprochene, von mir oben citirte Anschaunng über die Aetiologie des Dacryops scheint keine allgemeine Gültigkeit beanspruchen zu dürfen. Die sowohl im Francke'schen als anch in meinem Falle beobachtete, ziemlich reichliche kleinzellige Infiltration des die Cyste überziehenden Conjunctivalgewebes könnte zu Gunsten einer entzündlichen Erkrankung des Letzteren gedeutet werden; - klinisch war in meinem Falle von einer solchen jedenfalls nichts zu entdecken, anch leugnete Patientin jemals eine Erkrankung ihres rechten Auges durchgemacht zu haben. Mir will es durchaus berechtigt erseheinen in meinem Falle die Lenkocytenansammlung im Conjunctivalgewebe, lediglich als Folge der durch den Druek der Cyste gestörten Cireulationsverhältnisse in demselben, d. h. als Folge einer venösen Stase der Bindehaut zu betrachten.

Nicht unerwähnt will ich lassen, dass ich meine Präparate der letzten Heidelberger Ophthalmologen-Versammlung vorgelegt habe. 


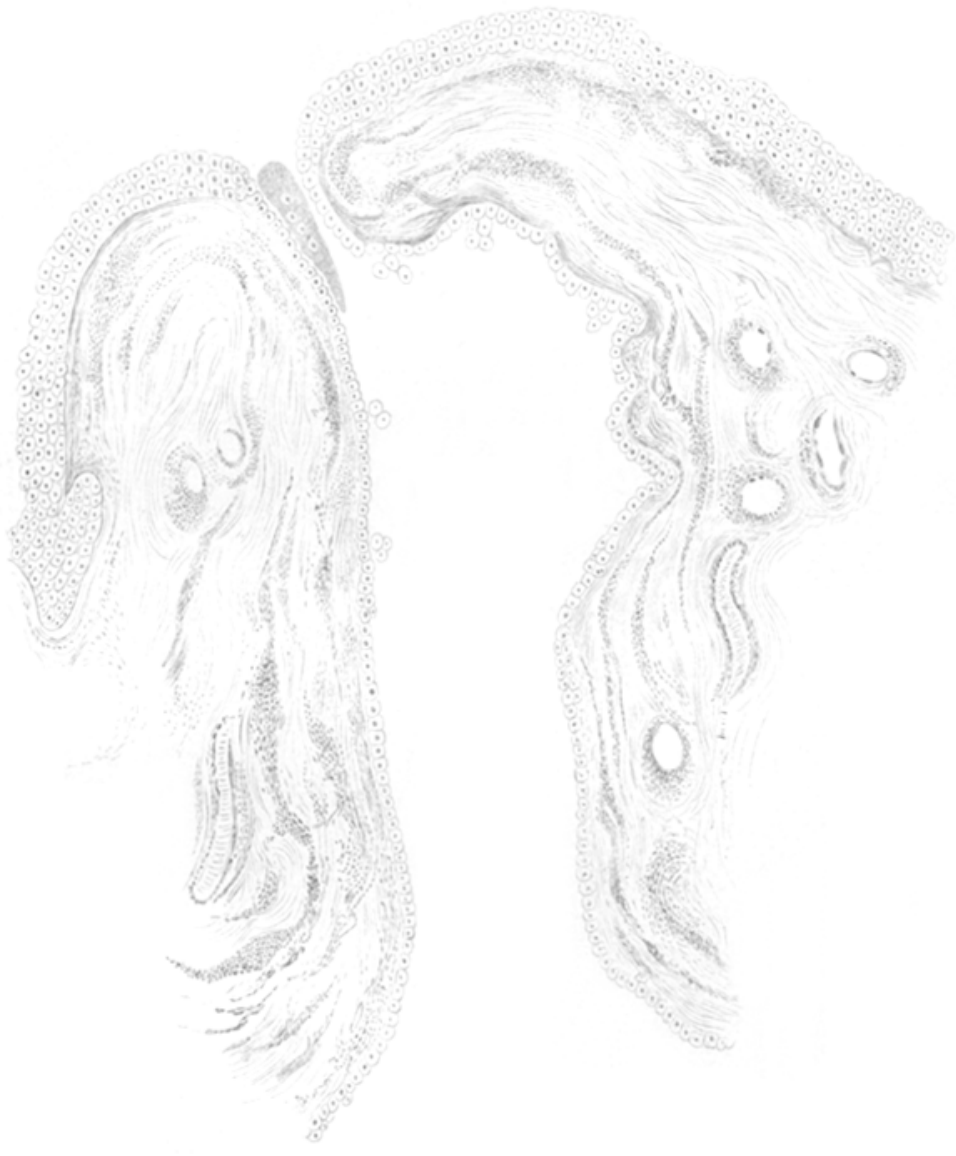

